\begin{tabular}{|c|l|}
\hline Title & Photochemical Control of Dark Conductivity : A New A pproach to Devices Based on Molecular Crystals \\
\hline Author(s) & Naito, T.; Sugawara, H.; I nabe, T.; Kitajima, Y.; Miyamoto, T.; Niimi, H.; A sakura, K. \\
\hline Citation & $\begin{array}{l}\text { Journal of Low Temperature Physics, 142(3-4), 387-390 } \\
\text { https://doi.org/10.1007/310909-006-9138-3 }\end{array}$ \\
\hline Issue Date & $2006-02$ \\
\hline Doc URL & http://hdl.handle.net/2115/26390 \\
\hline Rights & The original publication is available at www.springerlink.com \\
\hline Type & article (author version) \\
\hline File Information & JLTP142-387.pdf \\
\hline
\end{tabular}

Instructions for use 


\title{
Photochemical Control of Dark Conductivity - A New Approach to Devices Based on Molecular Crystals
}

\author{
T. Naito ${ }^{1,2}$, H. Sugawara ${ }^{2}$, T. Inabe ${ }^{2}$, Y. Kitajima ${ }^{3}$, T. Miyamoto ${ }^{4}$, \\ H. Niimi ${ }^{4}$, and K. Asakura ${ }^{4}$ \\ (1) Creative Research Initiative "Sousei" (CRIS), Hokkaido University, \\ Kita 21, Nishi 10, Kita-ku, Sapporo, Hokkaido, 001-0021 Japan \\ (2) Division of Chemistry, Graduate School of Science, Hokkaido University \\ (3) Institute of Materials Structure Science, Photon Factory (KEK-PF) \\ (4) Catalysis Research Center (CRC), Hokkaido University
}

Thermal analysis of $\mathrm{Ag}(D M)_{2}$, where $D M=2,5$-dimethyl- $N, N$ 'dicyanoquinonediimine, clarified that the salt had an insulating amorphous phase $\left(\geq 155^{\circ} \mathrm{C}\right)$. Characterization of this and related solid states of $A g(D M)_{2}$ indicated that a photo-induced process should be essential in controlling the number of carriers and thus conduction behavior of the salt by illumination. In fact, while heating could do nothing but make the salt insulating when the sample temperature exceeded $155^{\circ} \mathrm{C}$, ultraviolet-visible light illumination $\left(<155^{\circ} \mathrm{C}\right)$ could gradually change the properties to be semiconducting with retaining the crystal lattice (average structure).

PACS numbers: $82.30-b, 82.60$-s, 82.80.Ej.

\section{INTRODUCTION}

Recently, we developed a novel photochemical way of fabrication of molecular devices, which may enable simultaneous (persistent) carrier doping and photolithogarphy ${ }^{1}$. At present, we consider that this method is principally based on the same chemistry of silver halides photography. Instead of $\mathrm{AgBr}$, a silver salt of an organic $\pi$-acceptor $\mathrm{Ag}(\mathrm{DM})_{2}$, where $\mathrm{DM}$ $=2,5$-dimethyl- $N, N$ '-dicyanoquinonediimine, is illuminated with ultravioletvisible (UV-Vis) light. Due to the photosensitivity, the illuminated $\mathrm{Ag}^{+}$ions deprive the DM species of some $\pi$-conduction electrons. Let us suppose here that only a part of the sample be illuminated and thus the rest (nonilluminated part) of the solid remain unchanged. One could make different parts with different conducting properties in a single crystal, i.e. a junction structure; a fundamental form of current devices. Consequently, a single crystal of $\mathrm{Ag}(\mathrm{DM})_{2}$ can be transformed to have a junction structure after appropriately partial illumination. Irreversibility and high spatial resolution 


\section{T. Naito, H. Sugawara, T. Inabe, Y. Kitajima, T. Miyamoto, H. Niimi, and K. Asakura}

of photochemistry are found to be advantageous in this kind of fabrications. In order to establish and generalize this method, we should understand more detailed mechanism of the "optical doping" method. In this paper we will briefly discuss whether heat should involve and whether the crystal structure should retain during the UV-Vis illumination on $\mathrm{Ag}(\mathrm{DM})_{2}$ based on the results of chemical, spectral and thermal analyses ${ }^{2}$.

\section{EXEPRIMENTAL}

The crystalline sample of $\operatorname{Ag}(\mathrm{DM})_{2}$ were obtained by a reported method $^{3}$. Illumination was carried out in an open atmosphere at room temperature using a $\mathrm{Hg} / \mathrm{Xe}$ lamp (200 W) equipped with a multimode optical fiber $(8 \mathrm{~mm} \phi)$, a heat ray cutoff filter and a cold mirror. Also examined were dependencies on wavelengths and intensities of the incident light as well as duration of illumination. Thermal analysis (DSC and TGA) were conducted on the samples sealed in aluminum pans $\left(7 \times 7 \times 0.25 \mathrm{~mm}^{3}\right)$.

\section{RESULTS AND DISCUSSION}

We obtained four different kinds of resultant states depending on the illumination conditions. Among them including the pristine material, let us concentrate our discussion on the following three, and tentatively call these series of states $\alpha, \beta$ and $\gamma$, respectively (Fig. 1).

On UV-Vis illumination around room temperature (RT), the original metallic properties of the pristine material $(\alpha)$ gradually turned to be semiconducting $(\beta)$. Compared with the pristine $(\alpha-)$ state, the $\beta$-state exhibited differed electrical behavior, Raman shifts $(C=C$ and $C=N$ stretching modes) and X-ray photoelectron spectra (Ag, N) with unchanged XRD pattern, elemental analyses ( $\mathrm{C}, \mathrm{H}, \mathrm{N}$ ) and infrared (IR) absorption spectra. When the sample temperature exceeded $155^{\circ} \mathrm{C}$ during the illumination, an irreversible structural transition occurred; the dark blue crystalline sample $(\alpha)$ suddenly turned to be light brown amorphous solid retaining the original clear-cut shape of each single crystal $(\gamma)$. The $\gamma$-state turned out to be insulating and diamagnetic from the electrical resistivity and the magnetic susceptibility measurements. From the experimental results below, it is concluded that at $155^{\circ} \mathrm{C}$ a solid state redox reaction, i.e. electron transfer, occcurs between the $\mathrm{Ag}^{+}$ions and the DM radical anions, leading both chemical species to neutral states. Because the heat of reaction is considered to overwhelm that of amorphization in this case, a clear exothermic heat $\left(\Delta H=-126.8 \mathrm{kJmol}^{-1}\right)$ was observed in the measurements 


\section{Photochemical Control of Dark Conductivity - A New Approach to Devices Based on Molecular Crystals}
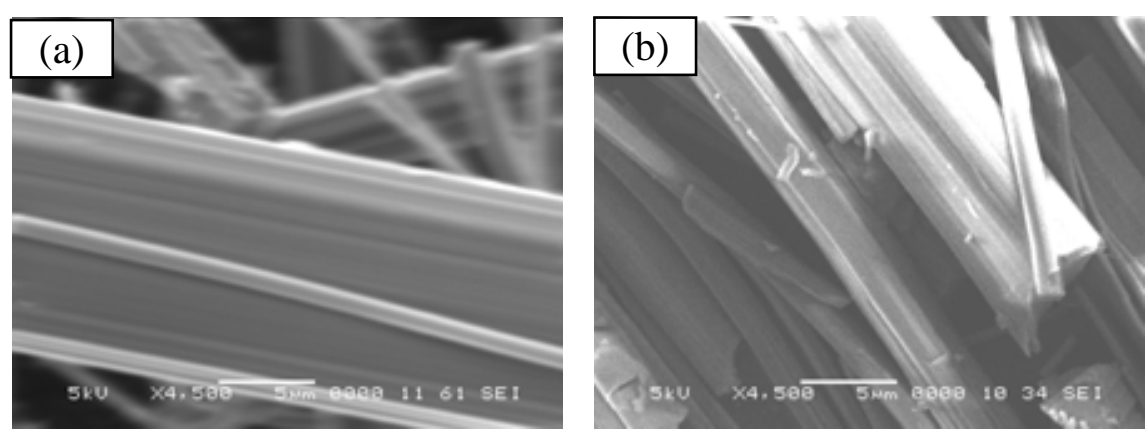

Fig. 1. Scanning Electron Microprobe (SEM) photographs of different states after UV-Vis illumination on single crystals of $\operatorname{Ag}(\mathrm{DM})_{2}$; (a) $\beta$-, and (b) $\gamma$-states, respectively. The SEM photographs of the pristine $(\alpha-)$ samples (not shown here) much resemble those of the $\beta$-state.

of differential scanning calorimetry (DSC) (Fig. 2). Elemental analyses and thermogravimetric and differential thermal analysis (TG-DTA) indicated that the chemical stoichiometry of $\operatorname{Ag}(\mathrm{DM})_{2}$ was substantially retained through the structural transition. Solid state NMR $\left({ }^{13} \mathrm{C}\right)$ and IR absorption spectra indicated that the molecular structure of DM remained without decomposition in the $\gamma$-state. Furthermore, X-ray absorption fine structure (XAFS) indicated that the $\gamma$-state included neutral silver instead of $\mathrm{Ag}^{+}$ions. Yet the material exhibited different spectroscopic and chemical properties from a mixture of bulk silver and neutral DM species. The $\gamma$-state could not be separated into the two components by standard chemical procedures of purification. All these data suggest that the $\gamma$-state should correspond to a single phase comprised of neutral Ag and DM species.

In Fig. 2, except for the exothermic peak, only clear plateau was observed at all the temperature, which means that nothing should occur below $155^{\circ} \mathrm{C}$. Accordingly, heat can only produce the totally insulating $\gamma$-state at $155^{\circ} \mathrm{C}$ or can not make any difference in the physical properties of $\mathrm{Ag}(\mathrm{DM})_{2}$ below $155^{\circ} \mathrm{C}$. On illumination, the pristine solid, whether it is a single crystal or powder, turns into the amorphous state all at once. The findings about the $\gamma$-state indicate that the $\beta$-state could NOT be produced by heat, because the single crystals of $\operatorname{Ag}(\mathrm{DM})_{2}$ in the $\beta$-state are known to progressively become semiconducting in accordance with illumination ${ }^{1}$. Detailed structural information of the $\beta$-state, particularly the difference from the $\alpha$-state, is evidently required, which is now under investigation. 
T. Naito, H. Sugawara, T. Inabe, Y. Kitajima, T. Miyamoto, H. Niimi, and K. Asakura

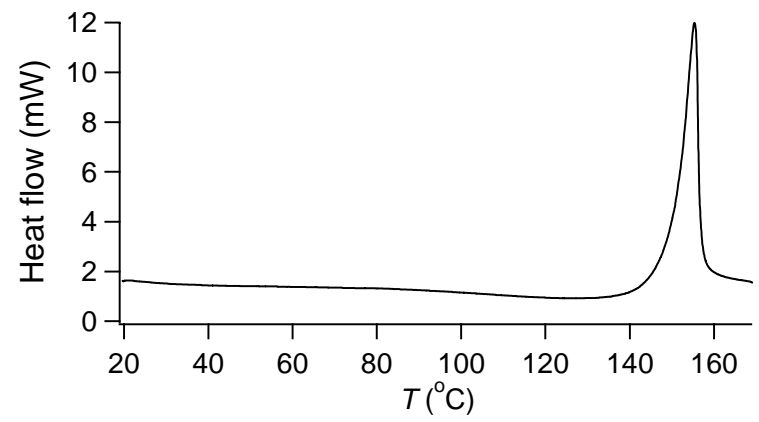

Fig. 2. Differential scanning calorimetry of $\mathrm{Ag}(\mathrm{DM})_{2}$ (6.600 mg). Heating rate was $3{ }^{\circ} \mathrm{Cmin}^{-1}$. Identical results were obtained when the measurements were carried out in air and in dry nitrogen.

\section{CONCLUSIONS}

At $155^{\circ} \mathrm{C}$, an irreversible crystal-amorphous transition of $\mathrm{Ag}(\mathrm{DM})_{2}$ is found and the amorphous state is characterized to be diamagnetic and insulating, comprised of neutral silver and DM species. We did not observe an intermediate or mixed situation between the pristine and the $\gamma$-states that could be produced by heating, regardless of the heating conditions. Thus it can be concluded that a photo-induced process, instead of thermal effects, has turned out to be essential in the spectral and electrical property changes observed in the illuminated $\operatorname{Ag}(\mathrm{DM})_{2}{ }^{1}$. In other words, the photochemical electron transfer (redox reaction) between the $\mathrm{Ag}^{+}$and the DM species ${ }^{1}$ is important in the phenomena in question, and no heating effects such as lattice defects or thermal decomposition could explain the phenomena as dominant origins.

\section{ACKNOWLEDGEMENTS}

We would like to thank Prof. Tooru Atake at Tokyo Institute of Technology for valuable discussion on the thermal analyses, and to Dr. Miho Sasaki at Rigaku Corporation for the XRD-DSC measurements.

\section{REFERENCES}

1. T. Naito, T. Inabe, H. Niimi and K. Asakura, Adv. Mater., 16, 1786 (2004).

2. More detailed manuscript is now in preparation.

3. S. Hünig et al., Eur. J. Inorg. Chem., 899 (1999). 